\title{
Complete genome sequence of Calditerrivibrio nitroreducens type strain (Yu37-1 $\left.{ }^{\mathrm{T}}\right)$
}

\author{
Sam Pitluck ${ }^{1}$, Johannes Sikorski ${ }^{2}$, Ahmet Zeytun ${ }^{1,3}$, Alla Lapidus ${ }^{1}$, Matt Nolan ${ }^{1}$, Susan Lucas ${ }^{1}$, \\ Nancy Hammon ${ }^{1}$, Shweta Deshpande ${ }^{1}$, Jan-Fang Cheng ${ }^{1}$, Roxane Tapia ${ }^{1,3}$, Cliff Han ${ }^{1,3}$, Lynne \\ Goodwin $^{1,3}$, Konstantinos Liolios ${ }^{1}$, Ioanna Pagani ${ }^{1}$, Natalia Ivanova ${ }^{1}$, Konstantinos \\ Mavromatis ${ }^{1}$, Amrita Pati ${ }^{1}$, Amy Chen ${ }^{4}$, Krishna Palaniappan ${ }^{4}$, Loren Hauser ${ }^{1,5}$, Yun-Juan \\ Chang $^{1,5}$, Cynthia D. Jeffries ${ }^{1,5}$, John C. Detter ${ }^{1}$, Evelyne Brambilla ${ }^{2}$, Oliver D. Ngatchou \\ Djao $^{6}$, Manfred Rohde ${ }^{6}$, Stefan Spring ${ }^{2}$, Markus Göker ${ }^{2}$, Tanja Woyke ${ }^{1}$, James Bristow ${ }^{1}$, \\ Jonathan A. Eisen ${ }^{1,7}$, Victor Markowitz ${ }^{4}$, Philip Hugenholtz ${ }^{1,8}$, Nikos C. Kyrpides ${ }^{1}$, \\ Hans-Peter Klenk ${ }^{2 *}$, and Miriam Land ${ }^{1,5}$ \\ ${ }^{1}$ DOE Joint Genome Institute, Walnut Creek, California, USA \\ ${ }^{2}$ DSMZ - German Collection of Microorganisms and Cell Cultures GmbH, Braunschweig, \\ Germany \\ ${ }^{3}$ Los Alamos National Laboratory, Bioscience Division, Los Alamos, New Mexico, USA \\ ${ }^{4}$ Biological Data Management and Technology Center, Lawrence Berkeley National \\ Laboratory, Berkeley, California, USA \\ ${ }^{5}$ Oak Ridge National Laboratory, Oak Ridge, Tennessee, USA \\ ${ }^{6} \mathrm{HZI}$ - Helmholtz Centre for Infection Research, Braunschweig, Germany \\ ${ }^{7}$ University of California Davis Genome Center, Davis, California, USA \\ ${ }^{8}$ Australian Centre for Ecogenomics, School of Chemistry and Molecular Biosciences, The \\ University of Queensland, Brisbane, Australia \\ *Corresponding author: Hans-Peter Klenk
}

Keywords: moderately thermophilic, strictly anaerobic, motile, Gram-negative, chemoorganoheterotroph, hot spring, Deferribacteraceae, GEBA

Calditerrivibrio nitroreducens lino et al. 2008 is the type species of the genus Calditerrivibrio. The species is of interest because of its important role in the nitrate cycle as nitrate reducer and for its isolated phylogenetic position in the Tree of Life. Here we describe the features of this organism, together with the complete genome sequence and annotation. This is the third complete genome sequence of a member of the family Deferribacteraceae. The 2,216,552 bp long genome with its 2,128 protein-coding and 50 RNA genes is a part of the Genomic Encyclopedia of Bacteria and Archaea project.

\section{Introduction}

Strain Yu37-1 ${ }^{\mathrm{T}}$ (= DSM 19672 = NBRC 101217) is the type strain of Calditerrivibrio nitroreducens which in turn is the type and sole species of the genus Calditerrivibrio [1]. The genus Calditerrivibrio is one out of six genera in the family Deferribacteraceae [2-6]. The genus name is derived from Latin adjective "caldus", hot, "terra", the earth, and "vibrio", a vibrio, referring to a vibroid shaped bacterium in a hot terrestrial environment. The species epithet nitroreducens derives from the Greek name "nitron", nitrite, nitrate, and "reducens", drawing backwards, referring to its nitratereducing physiology [1]. Strain Yu37-1 ${ }^{\mathrm{T}}$ was iso- lated from hot-spring water from Yumata, Nagano, Japan. No further cultivated strains belonging to the species $C$. nitroreducens have been described so far. Here we present a summary classification and a set of features for $C$. nitroreducens strain Yu37-1 ${ }^{\mathrm{T}}$, together with the description of the complete genomic sequencing and annotation.

\section{Classification and features}

A representative genomic 16S rRNA sequence of strain Yu37-1 $1^{\mathrm{T}}$ was compared using BLAST under default settings (e.g., considering only only the 
high-scoring segment pairs (HSPs) from the best 250 hits) with the most recent release of the Greengenes database [7] and the relative frequencies of taxa and keywords (reduced to their stem [8]) were determined, weighted by BLAST scores. The most frequently occurring genera were Deferribacter (33.4\%), Alteromonas (21.3\%), Magnetococcus (9.4\%), Shuttleworthia (7.5\%) and Geovibrio (7.3\%) (61 hits in total). Regarding the single hit to sequences from members of the species, the average identity within HSPs was 99.9\%, whereas the average coverage by HSPs was $96.7 \%$. Among all other species, the one yielding the highest score was Deferribacter desulfuricans, which corresponded to an identity of $88.1 \%$ and an HSP coverage of $86.0 \%$. The highest-scoring environmental sequence was DQ424925 ('Enrichment and Thermophilic Mediator-Less Microbial Fuel Cell thermophilic microbial fuel cell enriched artificial wastewater clone 1B62') [9], which showed an identity of $99.7 \%$ and an HSP coverage of $98.2 \%$. The most frequently occurring keywords within the labels of environmental samples were 'microbiota' (4.1\%), 'microbi' (4.1\%), 'intestin' (4.0\%), 'mous' (3.8\%) and 'compet, exploit, inflamm, salmonella, typhimurium' (3.7\%) (183 hits in total). The most frequently occurring keywords within the labels of environmental samples which yielded hits of a higher score than the highest scoring species were 'microbi' (8.6\%), 'thermophil' (6.7\%), 'enrich' (5.7\%), 'cell, fuel' (5.3\%) and 'spring' (3.6\%) (21 hits in total), which seem to fit to the features known for $C$. nitroreducens.
Figure 1 shows the phylogenetic neighborhood of C. nitroreducens $\mathrm{Yu} 37-1^{\mathrm{T}}$ in a $16 \mathrm{~S}$ rRNA based tree. The two copies of the 16S rRNA gene in the genome differ by one nucleotide from each other any by up to one nucleotide from the previously published 16S rRNA sequence (AB364234).

Cells of the strain Yu37-1 $1^{\mathrm{T}}$ are vibrio-shaped, 0.4$0.5 \times 1.4-2.0 \mu \mathrm{m}$ in size, occur singly or in pairs and stain Gram-negative [1] (Table 1 and Figure 2). No spore formation was detected for Yu37-1 ${ }^{\mathrm{T}}$ [1]. No data is available on the generation time of strain Yu37-1 ${ }^{\mathrm{T}}$. Nitrate is the only electron acceptor utilized, with ammonium as the end product [1]. Elemental sulfur, sulfate, sulfite, nitrite, iron (III) oxide, manganese (IV) oxide, selenate, selenite, arsenate, arsenite, fumarate and oxygen are not used as alternative electron acceptors [1]. Acetate, pyruvate, lactate, fumarate, succinate, malate, yeast extract, peptone and Casamino acids are utilized as electron donors with nitrate as the electron acceptor; fermentative growth has not been observed [1]. Strain Yu37-1 $1^{\mathrm{T}}$ is strictly anaerobic and catalase negative [1].

\section{Chemotaxonomy}

The predominant compounds in whole cell lipids of $C$. nitroreducens strain Yu37-1 $1^{\mathrm{T}}$ are saturated branched-chain fatty acids: iso- $\mathrm{C}_{14: 0}(26.3 \%)$, anteiso- $\mathrm{C}_{15: 0}(24.1 \%)$, iso- $\mathrm{C}_{13: 0}(7.7 \%), \mathrm{C}_{18: 0}(7.2 \%)$, $\mathrm{C}_{16: 0}(6.2 \%)$, iso- $\mathrm{C}_{16: 0}(5.7 \%)$ and anteiso- $\mathrm{C}_{13: 0}$ (5.3\%) [1]. Menaquinone MK-8 was identified as the major quinone [1].

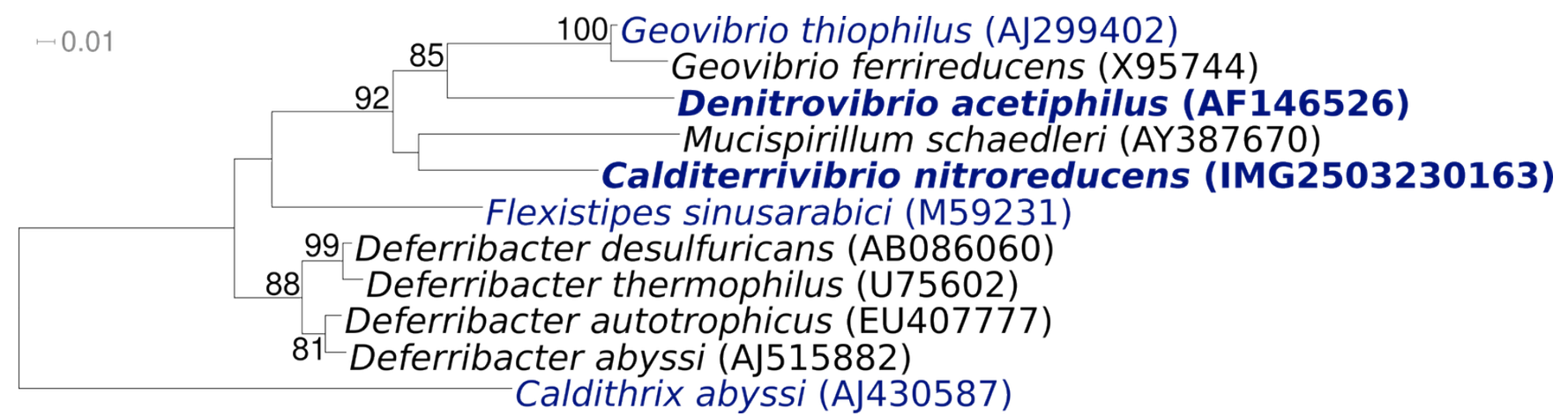

Figure 1. Phylogenetic tree highlighting the position of $C$. nitroreducens $\mathrm{Yu} 37-1^{\top}$ relative to the other type strains within the family Deferribacteraceae. The tree was inferred from 1,470 aligned characters [10,11] of the 16S rRNA gene sequence under the maximum likelihood criterion [12] and rooted in accordance with the current taxonomy. The branches are scaled in terms of the expected number of substitutions per site. Numbers above branches are support values from 1,000 bootstrap replicates [13] if larger than 60\%. Lineages with type strain genome sequencing projects registered in GOLD [14] are shown in blue, published genomes in bold [15]. 


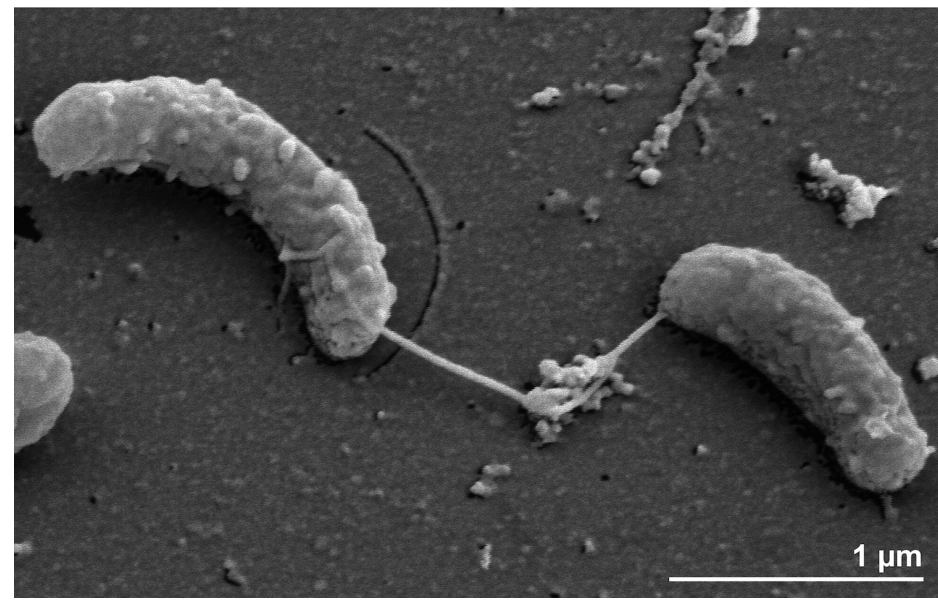

Figure 2. Scanning electron micrograph of $C$. nitroreducens $\mathrm{Yu} 37-1^{\top}$

Table 1. Classification and general features of $C$. nitroreducens $\mathrm{Yu} 37-1^{\top}$ according to the MIGS recommendations [16]

\begin{tabular}{|c|c|c|c|}
\hline MIGS ID & Property & Term & Evidence code \\
\hline & \multirow{8}{*}{ Current classification } & Domain Bacteria & TAS [17] \\
\hline & & Phylum Deferribacteres & TAS [18-20] \\
\hline & & Class Deferribacteres & TAS $[18,21]$ \\
\hline & & Order Deferribacterales & TAS $[18,22]$ \\
\hline & & Family Deferribacteraceae & TAS $[18,23]$ \\
\hline & & Genus Calditerrivibrio & TAS [1] \\
\hline & & Species Calditerrivibrio nitroreducens & TAS [1] \\
\hline & & Type strain Yu37-1 & TAS [1] \\
\hline & Gram stain & negative & TAS [1] \\
\hline & Cell shape & vibrio-shaped & TAS [1] \\
\hline & Motility & motile, single polar flagellum & TAS [1] \\
\hline & Sporulation & none & TAS [1] \\
\hline & Temperature range & $30^{\circ} \mathrm{C}-65^{\circ} \mathrm{C}$ & TAS [1] \\
\hline & Optimum temperature & $55^{\circ} \mathrm{C}$ & TAS [1] \\
\hline & Salinity & $<0.5 \% \mathrm{NaCl}$ & TAS [1] \\
\hline \multirow[t]{3}{*}{ MIGS-22 } & Oxygen requirement & strictly anaerobic & TAS [1] \\
\hline & Carbon source & carbohydrates & TAS [1] \\
\hline & Energy source & chemoorganoheterotrophic & TAS [1] \\
\hline MIGS-6 & Habitat & hot spring & TAS [1] \\
\hline MIGS-15 & Biotic relationship & not reported & \\
\hline \multirow[t]{3}{*}{ MIGS-14 } & Pathogenicity & not reported & \\
\hline & Biosafety level & 1 & TAS [24] \\
\hline & Isolation & hot spring water & TAS [1] \\
\hline MIGS-4 & Geographic location & Yumata, Nagano, Japan & TAS [1] \\
\hline MIGS-5 & Sample collection time & 2008 or before & TAS [1] \\
\hline MIGS-4.1 & Latitude & 36.83 & TAS [1] \\
\hline MIGS-4.2 & Longitude & 138.22 & TAS [1] \\
\hline MIGS-4.3 & Depth & $0 \mathrm{~m}$, surface waters & TAS [1] \\
\hline MIGS-4.4 & Altitude & not reported & \\
\hline
\end{tabular}

Evidence codes - IDA: Inferred from Direct Assay (first time in publication); TAS: Traceable Author Statement (i.e., a direct report exists in the literature); NAS: Non-traceable Author Statement (i.e., not directly observed for the living, isolated sample, but based on a generally accepted property for the species, or anecdotal evidence). These evidence codes are from of the Gene Ontology project [25]. If the evidence code is IDA, then the property was directly observed by one of the authors or an expert mentioned in the acknowledgements. 


\section{Genome sequencing and annotation}

\section{Genome project history}

This organism was selected for sequencing on the basis of its phylogenetic position [26], and is part of the Genomic Encyclopedia of Bacteria and Archaea project [27]. The genome project is deposited in the Genomes On Line Database [14] and the complete genome sequence is deposited in GenBank. Sequencing, finishing and annotation were performed by the DOE Joint Genome Institute (JGI). A summary of the project information is shown in Table 2.

Table 2. Genome sequencing project information

\begin{tabular}{|c|c|c|}
\hline MIGS ID & Property & Term \\
\hline MIGS-31 & Finishing quality & Finished \\
\hline MIGS-28 & Libraries used & $\begin{array}{l}\text { Tree genomic libraries: one } 454 \text { pyrosequence standard library, } \\
\text { one } 454 \text { PE library ( } 7 \text { kb insert size), one Illumina library }\end{array}$ \\
\hline MIGS-29 & Sequencing platforms & Illumina GAii, 454 GS FLX Titanium \\
\hline MIGS-31.2 & Sequencing coverage & $150.7 \times$ Illumina; $68.8 \times$ pyrosequence \\
\hline MIGS-30 & Assemblers & Newbler version 2.5-internal-10Apr08-1-threads, Velvet, phrap \\
\hline \multirow[t]{6}{*}{ MIGS-32 } & Gene calling method & Prodigal 1.4, GenePRIMP \\
\hline & INSDC ID & $\begin{array}{l}\text { CP002347 (chromosome) } \\
\text { CP002348 (plasmid) }\end{array}$ \\
\hline & Genbank Date of Release & December 7, 2010 \\
\hline & GOLD ID & Gc01554 \\
\hline & NCBI project ID & 49523 \\
\hline & Database: IMG-GEBA & 2503707001 \\
\hline \multirow[t]{2}{*}{ MIGS-13 } & Source material identifier & DSM 19672 \\
\hline & Project relevance & Tree of Life, GEBA \\
\hline
\end{tabular}

\section{Growth conditions and DNA isolation}

C. nitroreducens Yu37-1', DSM 19672, was grown anaerobically in DSMZ medium 1112 (Calditerrivibrio medium) [28] at $55^{\circ} \mathrm{C}$. DNA was isolated from $0.5-1 \mathrm{~g}$ of cell paste using Qiagen Genomic 500 DNA Kit (Qiagen, Hilden, Germany) following the standard protocol as recommended by the manufacturer, with modification st/DL for cell lysis as described in [27]. DNA is available through the DNA Bank Network [29].

\section{Genome sequencing and assembly}

The genome was sequenced using a combination of Illumina and 454 sequencing platforms. All general aspects of library construction and sequencing can be found at the JGI website [30]. Pyrosequencing reads were assembled using the Newbler assembler (Table 2). The initial Newbler assembly, consisting of seven contigs in four scaffolds, was converted into a phrap assembly [31] by making fake reads from the consensus to collect the read pairs in the 454 paired end library. Illumina GAii sequencing data (334.0 Mb) was assembled with Velvet [32] and the consensus sequences were shredded into $1.5 \mathrm{~kb}$ overlapped fake reads and assembled together with the 454 data. The 454 draft assembly was based on $152.9 \mathrm{Mb}$ of 454 draft data and all of the 454 paired end data. Newbler parameters are consed -a 50 -l 350 -g -m -ml 20. The Phred/Phrap/ Consed software package [31] was used for sequence assembly and quality assessment in the subsequent finishing process. After the shotgun stage, reads were assembled with parallel phrap (High Performance Software, LLC). Possible misassemblies were corrected with gapResolution [30], Dupfinisher [33], or sequencing cloned bridging PCR fragments with subcloning or transposon bombing (Epicentre Biotechnologies, Madison, WI). Gaps between contigs were closed by editing in Consed, by PCR and by Bubble PCR primer walks (J.-F.Chang, unpublished). A total of 24 additional reactions were necessary to close gaps and to raise the quality of the finished sequence. Illumina reads were also used to correct potential base errors and increase consensus quality using a software Polisher developed at JGI [34]. The error rate of the completed genome sequence is less than 1 in 100,000 . Together, the combination of the Illumina and 454 sequencing platforms provided $219.5 \times$ coverage of the genome. The final assembly contained 438,623 pyrosequence and 43,957,307 Illumina reads. 


\section{Genome annotation}

Genes were identified using Prodigal [35] as part of the Oak Ridge National Laboratory genome annotation pipeline, followed by a round of manual curation using the JGI GenePRIMP pipeline [36]. The predicted CDSs were translated and used to search the National Center for Biotechnology Information (NCBI) nonredundant database, UniProt, TIGRFam, Pfam, PRIAM, KEGG, COG, and InterPro databases. Additional gene prediction analysis and functional annotation was performed within the Integrated Microbial Genomes - Expert Review (IMG-ER) platform [37].

\section{Genome properties}

The genome consists of a 2,157,835 bp long chromosome with a $36 \%$ GC content and a 58,717 bp plasmid with $31 \%$ GC content (Figures $3 \mathrm{a}$ and $3 \mathrm{~b}$ and Table 3). Of the 2,278 genes predicted, 2,128 were protein-coding genes, and 50 RNAs; 27 pseudogenes were identified. The majority of the protein-coding genes $(76.5 \%)$ were assigned with a putative function while the remaining ones were annotated as hypothetical proteins. The distribution of genes into COGs functional categories is presented in Table 4.

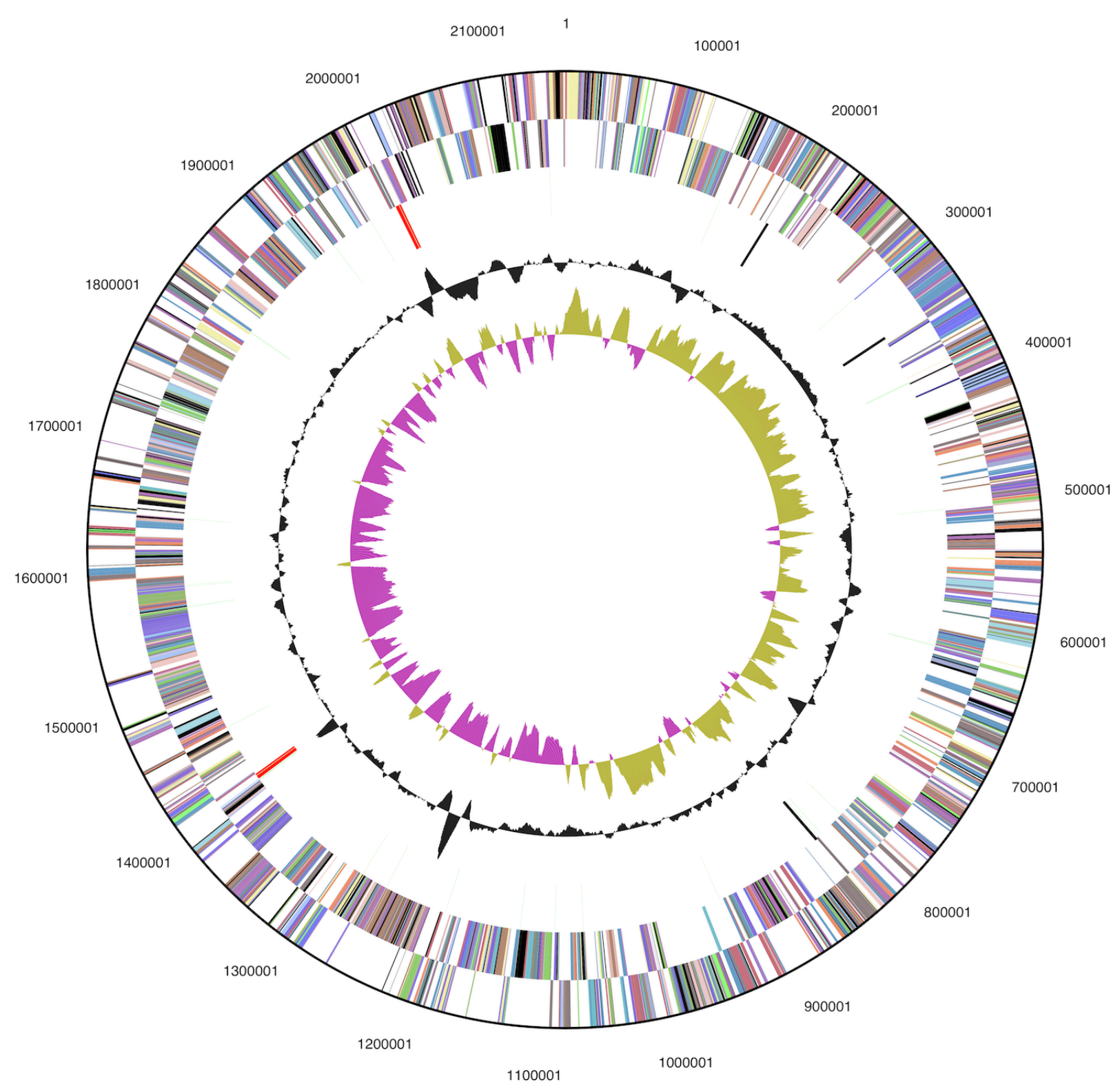

Figure 3a. Graphical circular map of the chromosome. From outside to the center: Genes on forward strand (color by COG categories), Genes on reverse strand (color by COG categories), RNA genes (tRNAs green, rRNAs red, other RNAs black), GC content, GC skew. 


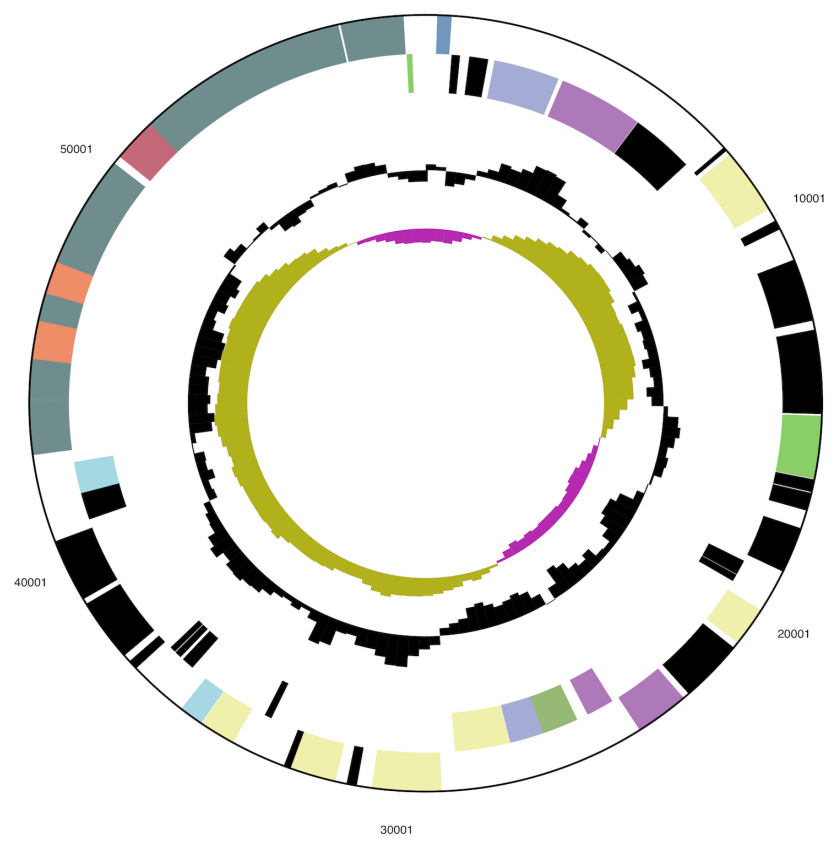

Figure 3b. Graphical circular map of the plasmid (not drown to scale with chromosome). From outside to the center: Genes on forward strand (color by COG categories), Genes on reverse strand (color by COG categories), RNA genes (tRNAs green, rRNAs red, other RNAs black), GC content, GC skew.

Table 3. Genome Statistics

\begin{tabular}{lrr}
\hline Attribute & Value & \% of Total \\
\hline Genome size (bp) & $2,216,552$ & $100.00 \%$ \\
DNA coding region (bp) & $2,076,059$ & $93.66 \%$ \\
DNA G+C content (bp) & 789,723 & $35.63 \%$ \\
Number of replicons & 2 & \\
Extrachromosomal elements & 1 & \\
Total genes & 2,178 & $100.00 \%$ \\
RNA genes & 50 & $2.30 \%$ \\
rRNA operons & 2 & \\
Protein-coding genes & 2,128 & $97.70 \%$ \\
Pseudo genes & 27 & $1.24 \%$ \\
Genes with function prediction & 1,666 & $76.49 \%$ \\
Genes in paralog clusters & 190 & $8.72 \%$ \\
Genes assigned to COGs & 1,731 & $79.48 \%$ \\
Genes assigned Pfam domains & 1,800 & $82.64 \%$ \\
Genes with signal peptides & 295 & $13.54 \%$ \\
Genes with transmembrane helices & 520 & $23.88 \%$ \\
CRISPR repeats & 3 & \\
\hline
\end{tabular}


Table 4. Number of genes associated with the general COG functional categories

\begin{tabular}{lrrl}
\hline Code & value & \%age & Description \\
\hline J & 141 & 7.4 & Translation, ribosomal structure and biogenesis \\
A & 0 & 0.0 & RNA processing and modification \\
K & 78 & 4.1 & Transcription \\
L & 96 & 5.0 & Replication, recombination and repair \\
B & 1 & 0.1 & Chromatin structure and dynamics \\
D & 22 & 1.2 & Cell cycle control, cell division, chromosome partitioning \\
Y & 0 & 0.0 & Nuclear structure \\
V & 34 & 1.8 & Defense mechanisms \\
T & 139 & 7.3 & Signal transduction mechanisms \\
M & 145 & 7.6 & Cell wall/membrane/envelope biogenesis \\
N & 81 & 4.3 & Cell motility \\
Z & 0 & 0.0 & Cytoskeleton \\
W & 0 & 0.0 & Extracellular structures \\
U & 68 & 3.6 & Intracellular trafficking and secretion, and vesicular transport \\
O & 84 & 4.4 & Posttranslational modification, protein turnover, chaperones \\
C & 145 & 7.6 & Energy production and conversion \\
G & 67 & 3.5 & Carbohydrate transport and metabolism \\
E & 142 & 7.5 & Amino acid transport and metabolism \\
F & 53 & 2.8 & Nucleotide transport and metabolism \\
H & 112 & 5.9 & Coenzyme transport and metabolism \\
I & 58 & 3.0 & Lipid transport and metabolism \\
P & 87 & 4.6 & Inorganic ion transport and metabolism \\
Q & 25 & 1.3 & Secondary metabolites biosynthesis, transport and catabolism \\
R & 214 & 11.2 & General function prediction only \\
S & 113 & 5.9 & Function unknown \\
- & 447 & 20.5 & Not in COGs \\
\hline
\end{tabular}

\section{Acknowledgements}

We would like to gratefully acknowledge the help of Maren Schröder (DSMZ) for the growth of $C$. nitroreducens cultures. This work was performed under the auspices of the US Department of Energy Office of Science, Biological and Environmental Research Program, and by the University of California, Lawrence Berkeley National Laboratory under contract No. DE-AC02-

\section{References}

1. lino T, Nakagawa T, Mori K, Harayama S, Suzuki K. Calditerrivibrio nitroreducens gen. nov., sp. nov., a thermophilic, nitrate-reducing bacterium isolated from a terrestrial hot spring in Japan. Int J Syst Evol Microbiol 2008; 58:1675-1679. PubMed doi:10.1099/ijs.0.65714-0

2. Fiala G, Woese CR, Langworthy TA, Stetter KO. Flexistipes sinusarabici, a novel genus and species of eubacteria occurring in the Atlantis II Deep
05CH11231, Lawrence Livermore National Laboratory under Contract No. DE-AC52-07NA27344, and Los Alamos National Laboratory under contract No. DEAC02-06NA25396, UT-Battelle, and Oak Ridge National Laboratory under contract DE-AC05-000R22725, as well as German Research Foundation (DFG) INST 599/1-1.

brines of the Red Sea. Arch Microbiol 1990; 154:120-126. doi:10.1007/BF00423320

3. Greene AC, Patel BKC, Sheehy AJ. Deferribacter thermophilus gen. nov., sp. nov., a novel thermophilic manganese and iron-reducing bacterium isolated from a petroleum reservoir. Int I Syst Bacteriol 1997; 47:505-509. PubMed doi:10.1099/00207713-47-2-505

4. Myhr S, Torsvik T. Denitrovibrio acetiphilus, a novel genus and species of dissimilatory nitrate- 
reducing bacterium isolated from an oil reservoir model column. Int / Syst Evol Microbiol 2000; 50:1611-1619. PubMed

5. Caccavo F, Coates JD, Rossello-Mora RA, Ludwig W, Schleifer KH, Lovley DR, McInerney MJ. Geovibrio ferrireducens, a phylogenetically distinct dissimilatory Fe(III)-reducing bacterium. Arch Microbiol 1996; 165:370-376. PubMed doi:10.1007/s002030050340

6. Robertson BR, O'Rourke JL, Neilan BA, Vandamme P, On SLW, Fox JG, Lee A. Mucispirillum schaedleri gen. nov., sp. nov., a spiral-shaped bacterium colonizing the mucus layer of the gastrointestinal tract of laboratory rodents. Int J Syst Evol Microbiol 2005; 55:1199-1204. PubMed doi:10.1099/ijs.0.63472-0

7. DeSantis TZ, Hugenholtz $P$, Larsen N, Rojas M, Brodie E, Keller K, Huber T, Dalevi D, Hu P, Andersen $\mathrm{G}$. Greengenes, a chimera-checked $16 \mathrm{~S}$ rRNA gene database and workbench compatible with ARB. Appl Environ Microbiol 2006;

72:5069-5072. PubMed doi:10.1128/AEM.03006-05

8. Porter MF. An algorithm for suffix stripping. Program: electronic library and information systems 1980; 14:130-137.

9. Jong BC, Kim BH, Chang IS, Liew PW, Choo YF, Kang GS. Enrichment, performance, and microbial diversity of a thermophilic mediatorless microbial fuel cell. Environ Sci Technol 2006; 40:64496454. PubMed doi:10.1021/es0613512

10. Castresana J. Selection of conserved blocks from multiple alignments for their use in phylogenetic analysis. Mol Biol Evol 2000; 17:540-552. PubMed

11. Lee C, Grasso C, Sharlow MF. Multiple sequence alignment using partial order graphs. Bioinformatics 2002; 18:452-464. PubMed doi:10.1093/bioinformatics/18.3.452

12. Stamatakis A, Hoover P, Rougemont J. A rapid bootstrap algorithm for the RAxML web servers. Syst Biol 2008; 57:758-771. PubMed doi:10.1080/10635150802429642

13. Pattengale ND, Alipour M, Bininda-Emonds ORP, Moret BME, Stamatakis A. How many bootstrap replicates are necessary? Lect Notes Comput Sci 2009; 5541:184-200. doi:10.1007/978-3-64202008-7_13

14. Liolios K, Chen IM, Mavromatis K, Tavernarakis $\mathrm{N}$, Hugenholtz P, Markowitz VM, Kyrpides NC. The Genomes On Line Database (GOLD) in
2009: status of genomic and metagenomic projects and their associated metadata. Nucleic Acids Res 2010; 38:D346-D354. PubMed doi:10.1093/nar/gkp848

15. Kiss H, Lang E, Lapidus A, Copeland A, Nolan M, Rio TGD, Chen F, Lucas S, Tice H, Cheng JF, et al. Complete genome sequence of Denitrovibrio acetiphilus type strain $\left(\mathrm{N} 2460^{\top}\right)$. Stand Genomic Sci 2010; 2:270-279. PubMed doi:10.4056/sigs.892105

16. Field D, Garrity G, Gray T, Morrison N, Selengut J, Sterk P, Tatusova T, Thomson N, Allen MJ, Angiuoli SV, et al. The minimum information about a genome sequence (MICS) specification. Nat Biotechnol 2008; 26:541-547. PubMed doi:10.1038/nbt1360

17. Woese CR, Kandler O, Wheelis ML. Towards a natural system of organisms: proposal for the domains Archaea, Bacteria, and Eucarya. Proc Natl Acad Sci USA 1990; 87:4576-4579. PubMed doi:10.1073/pnas.87.12.4576

18. Validation list 85: Validation of publication of new names and new combinations previously effectively published outside the IJSEM. Int I Syst Evol Microbiol 2002; 52:685-690. PubMed doi:10.1099/ijs.0.02358-0

19. Garrity GM, Holt JG. Phylum BIX. Deferribacteres phy. nov. In Bergey's Manual of Systematic Bacteriology, 2nd edn, vol. 1 (The Archaea and the Deeply Branching and Phototrophic Bacteria), Edited by D. R. Boone, R. W. Castenholz and G. M. Garrity. New York: Springer 2001, pp.465471.

20. Jumas-Bilak E, Roudière L, Marchandin H. Description of 'Synergistetes' phyl. nov. and emended description of the phylum 'Deferribacteres' and of the family Syntrophomonadaceae, phylum 'Firmicutes'. Int I Syst Evol Microbiol 2009; 59:1028-1035. PubMed doi:10.1099/ijs.0.006718-0

21. Huber H, Stetter KO. Class I. Deferribacteres class. nov. In Bergey's Manual of Systematic Bacteriology, 2nd edn, vol. 1 (The Archaea and the Deeply Branching and Phototrophic Bacteria), Edited by D. R. Boone, R. W. Castenholz and G. M. Garrity. New York: Springer 2001, pp. 465471.

22. Huber H, Stetter KO. Order I. Deferribacterales ord. nov. In Bergey's Manual of Systematic Bacteriology, 2nd edn, vol.1 (The Archaea and the Deeply Branching and Phototrophic Bacteria) 
Edited by D. R. Boone, R. W. Castenholz and G. M. Garrity. New York: Springer 2001:pp.465-471.

23. Huber H, Stetter KO. Family I. Deferribacteraceae fam. nov. In Bergey's Manual of Systematic Bacteriology, 2nd edn, vol. 1, Edited by D. R. Boone and R. W. Castenholz. New York: Springer 2002:pp. 465-466.

24. Classification of. Bacteria and Archaea in risk groups. http://www.baua.de TRBA 466.

25. Ashburner M, Ball CA, Blake JA, Botstein D, Butler $\mathrm{H}$, Cherry JM, Davis AP, Dolinski K, Dwight SS, Eppig JT, et al. Gene Ontology: tool for the unification of biology. Nat Genet 2000; 25:25-29. PubMed doi:10.1038/75556

26. Klenk HP, Göker M. En route to a genome-based classification of Archaea and Bacteria? Syst Appl Microbiol 2010; 33:175-182. PubMed doi:10.1016/j.syapm.2010.03.003

27. Wu D, Hugenholtz $P$, Mavromatis K, Pukall R, Dalin E, Ivanova NN, Kunin V, Goodwin L, Wu $M$, Tindall $B$ J, et al. A phylogeny-driven genomic encyclopaedia of Bacteria and Archaea. Nature 2009; 462:1056-1060. PubMed doi:10.1038/nature08656

28. List of growth media used at DSMZ: http://www.dsmz.de/microorganisms/media list.p hp.

29. Gemeinholzer B, Dröge $G$, Zetzsche H, Haszprunar G, Klenk HP, Güntsch A, Berendsohn WG, Wägele JW. The DNA Bank Network: the start from a German initiative. Biopreservation and Biobanking (In press).
30. DOE Joint Genome Institute. http://www.jgi.doe.gov

31. Phrap and Phred for Windows. MacOS, Linux, and Unix. http://www.phrap.com

32. Zerbino DR, Birney E. Velvet: algorithms for de novo short read assembly using de Bruijn graphs. Genome Res 2008; 18:821-829. PubMed doi:10.1101/gr.074492.107

33. Han C, Chain P. 2006. Finishing repeat regions automatically with Dupfinisher. in Proceeding of the 2006 international conference on bioinformatics \& computational biology. Edited by Hamid R. Arabnia \& Homayoun Valafar, CSREA Press. June 26-29, 2006: 141-146.

34. Lapidus A, LaButti K, Foster B, Lowry S, Trong S, Goltsman E. POLISHER: An effective tool for using ultra short reads in microbial genome assembly and finishing. AGBT, Marco Island, FL, 2008.

35. Hyatt D, Chen GL, Locascio PF, Land ML, Larimer FW, Hauser LJ. Prodigal: prokaryotic gene recognition and translation initiation site identification. BMC Bioinformatics 2010; 11:119. PubMed doi:10.1186/1471-2105-11-119

36. Pati A, Ivanova N, Mikhailova N, Ovchinikova G, Hooper SD, Lykidis A, Kyrpides NC. GenePRIMP: A gene prediction improvement pipeline for microbial genomes. Nat Methods 2010; 7:455-457. PubMed doi:10.1038/nmeth.1457

37. Markowitz VM, Ivanova NN, Chen IMA, Chu K, Kyrpides NC. IMG ER: a system for microbial genome annotation expert review and curation. Bioinformatics 2009; 25:2271-2278. PubMed doi:10.1093/bioinformatics/btp393 